Volume 9, No.3, May - June 2020

International Journal of Advanced Trends in Computer Science and Engineering

Available Online at http://www.warse.org/IJATCSE/static/pdf/file/ijatcse67932020.pdf

https://doi.org/10.30534/ijatcse/2020/67932020

\title{
Optimizing Sleep Time Slot for Bruxism and Insomnia Identification based on Frequency based EEG Patterns using Machine Learning Techniques
}

\author{
Shivam Tiwari ${ }^{1}$, Deepak Arora ${ }^{2}$, PuneetSharma ${ }^{3}$ \\ ${ }^{1,2,3}$ Department of Computer Science and Engineering, Amity University, Lucknow Campus, India \\ ${ }^{1}$ shivam.tiwari.info@gmail.com, 2deepakarorainbox@gmail.com,3puneetgrandmaster@gmail.com
}

\begin{abstract}
Many science researchers believe that a healthy thinking depends on the quality of human sleep. Giving importance to the quality sleeps, several systems for the measurement of sleep quality were developed. All the systems can be divided into two sections - Wearable Devices \& Automated devices. Exact estimation of the sleep quality by both the systems is quite difficult. Accurate assessment the quality of sleep depends on many physical and environmental factors such as dimension of bed, light effects, room temperature, any type of disease, oxygen level, etc. Accurately measurement these factors and establishing their relationship with sleep quality is a complex process. Measuring sleep quality through the systems currently available is not only complicated but also to a large extent expensive. This research attempts to summarize the systems available at present in measuring sleep quality. It divides the entire sleep-period into 4 parts and compares the accuracy of the predictions of the sleep related diseases at the end of each interval by applying machine-learning algorithms to the data of different time periods. In this research, diseases such as Insomnia and Bruxism have been included as a data set. With the results it is found that the slot $1(12: 00-1: 20)$ is the most important one in the processes of measuring sleep quality.
\end{abstract}

Key words: Quality of human sleep, Wearable device, Automated device, Insomnia, Bruxism, Machine learning, Sleep-period.

\section{INTRODUCTION}

Human life is influenced by 2 types of health (1) mental health (2) physical health. Treatment and check-up of physical health are possible in many general ways, while both mental health treatment and testing are parts of a complex process. The mental health depends on many factors such as the quantity of food, family problems, unemployment, environment, workload etc. Along with scientific development the mental diseases also got importance in medical science. Sleep problems have become important constituents of these mental diseases. To a large extent, the origin of mental diseases depends on the quality of sleep. Sleep disorder occurs when someone cannot sleep properly it results in loss function of the body organs and muscles [19].According to scientific researches, sleep is divided into two parts. First one is REM (Rapid Eye Movement), in this kind of sleep, human eyes keep on moving. Most of the dreams are part of this type of sleep. The second one is NRAM (NonRapid Eye Movement), in such sleeps a man doesn't see dreams. In such sleeps the brains are in a state of complete rest. The NRAM is also divided into several stages - S0, S1, S2, S3. These stages of sleep are further, gradually, divided into light and deep sleep states. All the experiments of estimating sleep quality are quite costly and time-consuming. In this research, attempts have been made to summarize the experiments that assess the quality of sleep, so that, to a great extent, experiments that assess the quality of sleep can be made easier. In this research, sleep is divided into 4 time periods - 12:00 - 1 : 20, 1: 00 - 2: 20, 2: 00 - 3: 20 and 3: 00 - 4: 20 are, respectively, Slot-1, Slot-2, Slot-3 and Slot-4. The research found that using multiple learning algorithms such as J-4, SVM, Naive Bayes, Random Forest, Knearest neighbour, Logistic Regression, the slot number one is of paramount importance in assessing the sleep quality. By this result it is proved that all the experiments which assess the quality of sleep can be more focused in slot 1 and can keep the time of the experiment and the subject away from the radiation emanating from the devices with electric impulses through which many other diseases caused by radiation can be avoided.

\section{LITERATURE REVIEW}

All previous researches can be divided into two parts: (1) Assessment of sleep quality with the help of wearable devices, (2) Assessment of sleep quality by automated equipment. Understanding the usefulness of sleep in human life, assessing the quality of sleep accurately has been a special subject matter for the researchers of all times. Several methods of assessing sleep quality have been developed from time to time, such as initially testing the movement above the subject's bed by load cell sensor grid, and understanding the quality of sleep by testing the leg movement using a linear classifier $[1,3]$. In this experiment, sleep stages were classified with $79.3 \%$ accuracy. In the year 2016, wearable devices made subjects feel uncomfortable due to which their sleep quality could not be estimated properly. So in this research, 48 FSR (Force Sensing Resistors) were installed under the bed and Sleep quality was tested under different error rates using class logistic regression. In this experiment $95.8 \%, 90.2 \%$ and $88.5 \%$ accuracies were found under the $4.2 \%, 9.7 \%$ and $11.5 \%$ error rate respectively [2]. According to Tseng et al. [4], an accurate 
assessment of sleep quality cannot be done by excluding electrical impulses originating in the human brain. In this experiment, electrical impulses originating in the human brain were recorded and the frequency of these electrical impulses were measured and the quality of sleep was understood based on the power of these frequencies. Here EEG signals were recorded through Bluetooth based device with the help of which the recorded data was sent to cloud storage for further processing. Since the brain signals are of very low voltage, the voltage signals were converted into frequency with the help of DAQ100 module for a good processing. In the year 2012, it was believed that a person spends one-third part of his entire life in sleeping. Understanding the importance of sleep in this research, many mathematical calculations were done and the formula of sleep index was calculated. And it was assumed that for different genders, estimation of sleep quality in different age groups is possible only under different sleep index [5]. Technology like IOT (Internet of Things) has made the research related to quality of sleep to a great extent easier. Through the research work conducted in the year 2016, IOT technology created a different image for itself. In these experiments, the possibility of adding noise signals to the sleep quality data was found to be very low which made the sleep quality measurement calculation easier [6]. Realizing the importance of sleep in human life, a momentum in sleep related research came when ultrasonic technology assessed the quality of sleep by examining the sonar generated movement on the subject's bed by an automated appliance. In this experiment, 62 subjects were tested. In this experiment, sleep was tested at different sleep stages and results with $87 \%, 89 \%, 84 \%$ accuracy were found in wake time, REM, and deep sleep stages, respectively [7]. Both methods of assessing sleep quality (by wearable devices \& by automated devices) have their own importance. Scientific research believes that wearable devices make the subject feel uncomfortable and it is a complex process to assess the quality of sleep properly. Whereas many noise factors are added to record sleep data by non-wearable device. Accurate assessment of sleep quality can be done by processing electrical impulses originating in the brain. The deep sleep index formula was calculated with the help of EEG recordings and force sensors, which is given below.

Deep Sleep Index $(D S I)=0.55 *$ No. of Small Movements $+1.05 *$ No. of Medium Movements $+1.02 *$ No. of Large Movements.

In this research work, $95.7 \%$ accuracy was recorded for deep sleep $[3,8,14,16,17]$. In the research conducted in the year 2018, it was believed that the breathing pattern is an important parameter in the quality of sleep. In this experiment, Sleep Disorder Breathing Algorithm was written and after implementation, 93\% accuracy was obtained [9, 16]. Sleep data was collected using I-Sleep sensors in an experiment conducted in the year 2019 and machine learning algorithms k-nearest neighbour, logistic regression and SVM were used to test the sleep quality. Results found $95.2 \%, 94.9 \%, 94.7 \%$ and $95.8 \%$ accuracy by k-nearest neighbour, logistic regression and SVM, respectively $[2,10]$. In another research conducted in the year 2019, it was assumed that different sleep patterns are seen at different locations, for different age groups \& different genders. In this research, electrical implants were divided into different frequency ranges - 0.5 - 4, 4- 8, 8-12 and 12-32 Hz, termed as delta, theta, alpha and beta respectively. The research found that the fluctuation in delta frequency is higher in females than in males. In this experiment, 10-20 instruments were used for EEG recordings [11, 17]. According to Ravan et al. [12], frequent use of the 10-20 system can cause brain related disorders and therefore such experiments should be avoided. Ravan introduces a Vagus Therapy. This research found that daily use of Vagus Therapy can enhance sleep quality. In this experiment $90 \%$ accuracy was achieved by using SVM algorithm [12]. All the researches in assessing the quality of sleep are in order to make experiments cheaper and simpler. In this order only, in the year 2017, a mobile application was developed, which was capable to measure major factors even like heart rate also. In this experiment the architecture of the application system is divided into 4 parts (1) data collection, (2) pre analysis (3) application role \& (4) result [13]. Most of the scientific researchers believe in the processing of EEG signals. Researchers suggest that EEG readings repeat itself at a particular intervals. Scientists call it Periodic K- alpha. Many scientific researches on these Periodic K-alpha confirm that these Periodic Kalpha are found in different patients in different diseases. Thus sleep quality index can be calculated with the help of Periodic K-alpha [14, 16, 17]. In 2011, research on narcolepsy patients considered that the Cyclic Alternative Pattern (CAP) is an important parameter in sleep quality assessment. Different CAP patterns were tested in all aspects of narcolepsy patients in this experiment.

Table 1: Summary of Literature Review

\begin{tabular}{|c|c|c|c|}
\hline Types & $\begin{array}{l}\text { Sensor/Tech } \\
\text { nology Used }\end{array}$ & Assessment & Reference \\
\hline \multirow{5}{*}{$\begin{array}{c}\text { Through } \\
\text { Wearable } \\
\text { Device }\end{array}$} & $\begin{array}{l}\text { Bluetooth } \\
\text { based EEG } \\
\text { device, } \\
\text { DAQ100 }\end{array}$ & $\begin{array}{l}\text { RAM takes } 25 \% \\
\text { of total sleep, } \\
\text { NRAM }(5 \%, \\
45 \%, 45 \%, 13 \% \\
\text { of } \\
\text { NRAM takes N1, } \\
\text { N2, N3, N4 } \\
\text { respectively) }\end{array}$ & [4] \\
\hline & $\begin{array}{l}\text { Theoretical } \\
\text { framework of } \\
\text { internet of } \\
\text { things }\end{array}$ & $\begin{array}{l}\text { A model is } \\
\text { proposed to } \\
\text { measure } \\
\text { sleep quality }\end{array}$ & [6] \\
\hline & $\begin{array}{l}\text { EEG device, } \\
\text { Force sensor }\end{array}$ & $\begin{array}{l}\text { Deep sleep index } \\
\text { formula is } \\
\text { calculated }\end{array}$ & $\begin{array}{l}{[8,14,16,17} \\
]\end{array}$ \\
\hline & $10-20$ system & $\begin{array}{l}\text { Different gender, } \\
\text { age shows } \\
\text { different EEG } \\
\text { pattern }\end{array}$ & {$[11,17]$} \\
\hline & EEG device & $\begin{array}{l}\text { CAP pattern is } \\
\text { important } \\
\text { parameter for } \\
\text { sleep study }\end{array}$ & {$[14,16,17]$} \\
\hline
\end{tabular}


Shivam Tiwari et al., International Journal of Advanced Trends in Computer Science and Engineering, 9(3), May - June 2020, 2926 - 2932

\begin{tabular}{|c|c|c|c|}
\hline & EEG device & $\begin{array}{l}\text { cyclic alternative } \\
\text { pattern is found } \\
\text { lesser in } \\
\text { narcolepsy } \\
\text { patient. }\end{array}$ & {$[14,15,17]$} \\
\hline \multirow{9}{*}{$\begin{array}{l}\text { Through } \\
\text { Self } \\
\text { Operating } \\
\text { Device }\end{array}$} & $\begin{array}{l}\text { Grid of 24- } \\
\mathrm{GHz} \\
\text { microwave } \\
\text { radar, Linear } \\
\text { discriminant } \\
\text { function }\end{array}$ & $\begin{array}{l}79.3 \% \text { accuracy } \\
\text { to classify Sleep } \\
\text { stages }\end{array}$ & {$[1]$} \\
\hline & $\begin{array}{l}\text { Force } \\
\text { sensing } \\
\text { resister, } \\
\text { Logistic } \\
\text { regression }\end{array}$ & $\begin{array}{l}>90 \% \text { accuracy in } \\
\text { classification }\end{array}$ & {$[2]$} \\
\hline & $\begin{array}{l}\text { Linear } \\
\text { classifier, } \\
\text { Load cell } \\
\text { sensor grid }\end{array}$ & $\begin{array}{l}97 \% \text { accuracy to } \\
\text { classify leg and } \\
\text { body movement }\end{array}$ & {$[1,3]$} \\
\hline & $\begin{array}{l}\text { Mathematical } \\
\text { calculation of } \\
\text { sleep index }\end{array}$ & $\begin{array}{l}\text { modified sleep } \\
\text { index formula }\end{array}$ & [5] \\
\hline & $\begin{array}{l}\text { Sonar } \\
\text { measurement }\end{array}$ & $\begin{array}{l}>84 \% \text { accuracy to } \\
\text { classify sleep } \\
\text { stages }\end{array}$ & [7] \\
\hline & $\begin{array}{l}\text { Sleep } \\
\text { disorder } \\
\text { breathing } \\
\text { algorithm is } \\
\text { written and } \\
\text { implemented }\end{array}$ & $\begin{array}{l}93 \% \text { accuracy to } \\
\text { classify breath } \\
\text { disorder }\end{array}$ & [9] \\
\hline & $\begin{array}{l}\text { A grid of } 48 \\
\text { pressure } \\
\text { sensor, KNN, } \\
\text { logistic } \\
\text { regression, } \\
\text { SVM, } \\
\text { random } \\
\text { forest }\end{array}$ & $\begin{array}{l}86.7 \% \text { accuracy } \\
\text { to detect sleep } \\
\text { posture, } 95.2 \% \text {, } \\
94.9 \%, 94.7 \% \text {, } \\
95.8 \% \text { accuracy } \\
\text { obtained by } \\
\text { KNN, logistic } \\
\text { regression, SVM, } \\
\text { and random } \\
\text { forest. }\end{array}$ & {$[2,10]$} \\
\hline & $\begin{array}{l}\text { Vagus nerve } \\
\text { therapy, } \\
\text { SVM }\end{array}$ & $\begin{array}{l}90 \% \text { accuracy to } \\
\text { classify epilepsy } \\
\text { patient }\end{array}$ & [12] \\
\hline & Oximeter & $\begin{array}{l}\text { System design } \\
\text { concept }\end{array}$ & [13] \\
\hline
\end{tabular}

\section{DATA SET AND EXPERIMENTAL SETUP}

Any type of research is incomplete without data. The accuracy of the result of the research depends on the accuracy of the data used in that research. The accuracy of the data depends on the way it is collected. Many times, due to some technical fault during data collection, there are unknown changes in the dataset. To perform the

research, the dataset can be collected or generated in two ways: first one, data collection by equipment, and the second one, previous collected data. Both processes have their own advantages. If someone wants to generate data, then many types of equipment will be needed such as 1020 systems, EEG device, force sensors, computing system and video recorder, etc. Data generation method totally depends on which method is used in research. Some researches suggested collecting data in a very efficient and on a very low cost manner such as Sonar application method. To generate sleep dataset it is very expensive. Let's talk about previous collected dataset. The accuracy of the result of the research depends on the accuracy of the data used in that research. So it is important to use dataset of only a very authentic organization. Some authentic organizations that should be recommended here are:(1) National Sleep Research Resource (https://sleepdata.org) \& (2) https://physionet.org/content/ capslpdb/1.0.0/. Both organizations have better collection of sleep datasets. Now the question is how to access sleep data from any authentic organization? Considering National Sleep Research Resource, one should register first with some basic details, signature, verify email and then submit it. After 2 or 3 days one will get a mail with download link. Now talk about Physionet, this is open source and no need to register, there is a download button to access the data which is more than $40 \mathrm{~GB}$. You can only download these files that you need in your research. The sleep pattern of Insomnia and Bruxism patients has been tested in this experiment. In this experiment the sleep patterns of 7 patients of Insomnia, 2 of Bruxism and 3 of No Pathology have been included. The aim of the research is to make sleep related experiments concise and easy. With this approach all 12 sleep pattern data sets in this research are divided into 4 time periods as follows 12:00 - 1:20, 1:00 - 2:20, 2:00 - 3:20 and 3:00 - 4:20, namely slot 1 , slot2, slot 3 and slot 4 respectively. Each slot is referred to an input data. Their sleep patterns were tested by applying machine learning algorithms to data sets of different time intervals. The experiment uses machine learning algorithms - J-48, SVM, Naive Bayes, RF, K-Nearest Neighbour, logistic regression. Results accuracy was found to be different at different time periods. The WEKA tool has been used in this research work. This research follows following flowchart, given in figure 1.

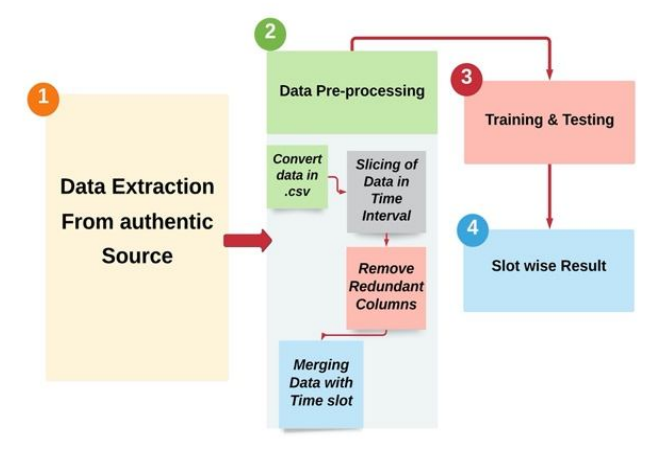

Figure 1: Experiment Flow chart 


\section{RESULT AND DISCUSSION}

In this research work, facts have been tested using 6 machine learning algorithms. In this experiment, the daily time period of sleep is considered around 7:00 pm - 7:00 am. The sleep related data is divided into 4 slots. In this research, the importance of sleep quality testing for every time period has been analyzed. The result found that slot1 (12:00 pm - 1:20 pm) plays an important role in improving sleep quality. Through this research it can be announced that the quality of sleep is dependent on slot-1. Therefore, sleep-related experiments need to focus more on slot- 1 and not elsewhere. On the basis of this research, it can be proved that the radioactive effects caused by electrical impulses can be reduced to a great extent. Many researches analyse the dangers of radioactive effects arising due to electrical impulses [16, 17, 18]. This research will prove effective to reduce the effects of radiation and to make the experiments related to sleep quality brief and simple. The following results were examined through accuracy distribution graph related to sleep quality given in figure 2 .

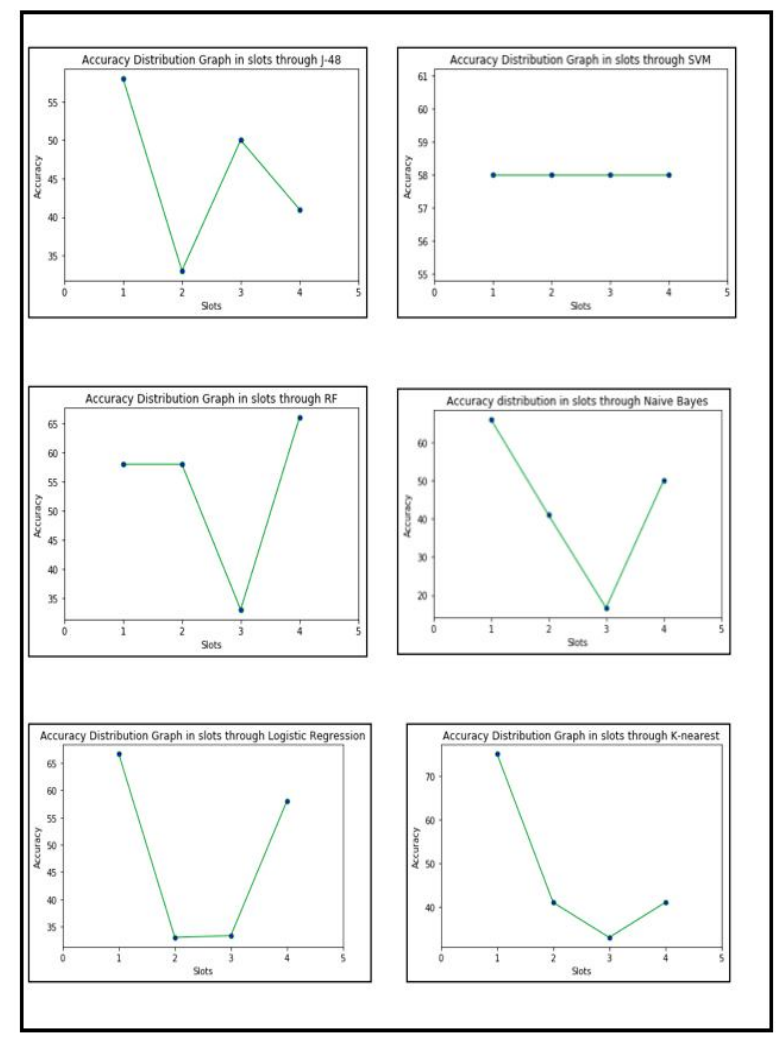

Figure 2: Accuracy Distribution in Sleep slots by Using J-48,SVM,LR, K-nearest,RF,Naive Bayes

Above figure 2 shows different machine learning algorithms show on an average same result of slot 1 have a crucial reason to measure quality of sleep. For better visualization of result, the accuracy distribution can be understood by taking average of all 6 machine learning algorithms in slots and draw a bar - chart as shown in figure 3 and Now considering 100 is the maximum buffer size then distribution of slot wise accuracy in buffer size can be drawn in pie chart in figure 4 .

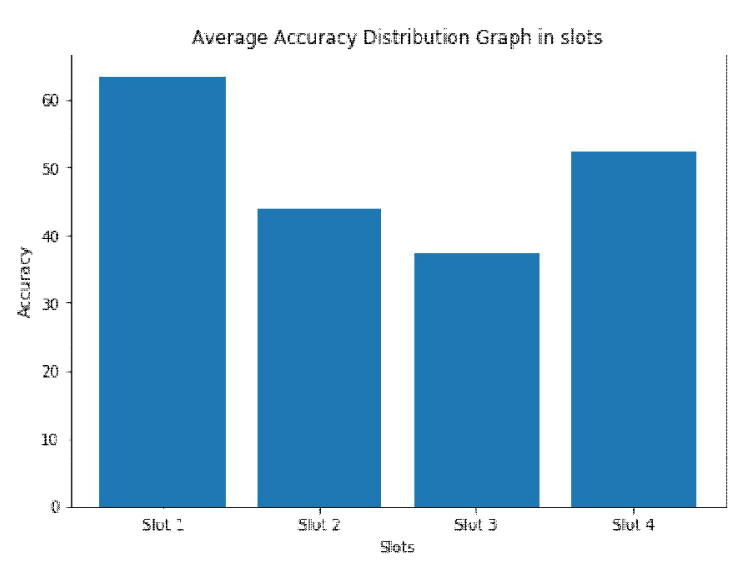

Figure 3: Average accuracy distribution graph in slots

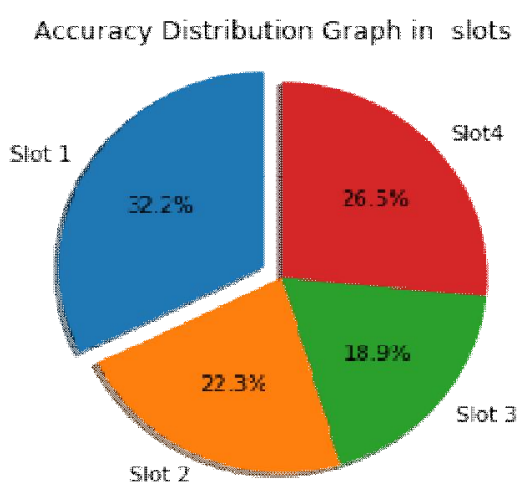

Figure 4: Accuracy distribution graph in slots (Buffer size $=100$ )

Obtained results (Table 2) through J-48, SVM, Naive Bayes, Random Forest, K-Nearest, Logistic Regression are shown in Table 2. The average results are $63.6 \%$, $44 \%, 37.33 \%$ and $52.33 \%$ in slot 1 , slot 2 , slot 3 and slot 4 respectively.

Table 2: Combined Accuracy Results

\begin{tabular}{|l|c|c|c|c|}
\hline $\begin{array}{l}\text { Algorit } \\
\text { hm } \\
\text { Name }\end{array}$ & $\begin{array}{l}\text { Slot 1 } \\
\text { Accurac } \\
\mathbf{y}\end{array}$ & $\begin{array}{l}\text { Slot 2 } \\
\text { Accurac } \\
\mathbf{y}\end{array}$ & $\begin{array}{l}\text { Slot 3 } \\
\text { Accurac } \\
\mathbf{y}\end{array}$ & $\begin{array}{l}\text { Slot 4 } \\
\text { Accurac } \\
\mathbf{y}\end{array}$ \\
\hline J-48 & 58 & 33 & 50 & 41 \\
\hline SVM & 58 & 58 & 58 & 58 \\
\hline $\begin{array}{l}\text { Naive } \\
\text { Bayes }\end{array}$ & 66 & 41 & 16.66 & 50 \\
\hline RF & 58 & 58 & 33 & 66 \\
\hline $\begin{array}{l}\text { K- } \\
\text { nearest }\end{array}$ & 75 & 41 & 33 & 41 \\
\hline $\begin{array}{l}\text { Logistic } \\
\text { Regress } \\
\text { ion }\end{array}$ & 66.6 & 33 & 33.33 & 58 \\
\hline
\end{tabular}


Shivam Tiwari et al., International Journal of Advanced Trends in Computer Science and Engineering, 9(3), May - June 2020, 2926 - 2932

Some important statistics are also calculated to justify the result these are - Kappa coefficient $(\mathrm{K})$, mean absolute error (MAE) and root mean square error (RMSE). To calculate Kappa statistics, the formula is used,

$$
K=1-\left((1-P) /\left(1-P^{\prime}\right)\right)
$$

Where P is the absolute probability and P' is the expected probability of success rate of classifier. Through the Results, shown in table 3, it can be examined that except slot-1, rest have negative Kappa coefficient that means slot 1 have maximum accuracy to measure sleep disorder.

Table 3: Kappa coefficient (K) results

\begin{tabular}{|l|c|c|c|c|}
\hline $\begin{array}{l}\text { Algorith } \\
\text { m Name }\end{array}$ & $\begin{array}{c}\text { Slot 1 } \\
\text { ( K- } \\
\text { coefficie } \\
\text { nt) }\end{array}$ & $\begin{array}{c}\text { Slot 2 } \\
\text { ( K- } \\
\text { coeffici } \\
\text { ent) }\end{array}$ & $\begin{array}{c}\text { Slot 3 } \\
\text { ( K- } \\
\text { coefficie } \\
\text { nt) }\end{array}$ & $\begin{array}{c}\text { Slot 4 } \\
\text { ( K- } \\
\text { coeffici } \\
\text { ent) }\end{array}$ \\
\hline J-48 & 0.0769 & -0.2468 & -0.1250 & -0.2174 \\
\hline SVM & 0.0000 & 0.0000 & 0.0000 & 0.0000 \\
\hline $\begin{array}{l}\text { Naive } \\
\text { Bayes }\end{array}$ & 0.4839 & 0.0345 & -0.2000 & 0.1628 \\
\hline RF & 0.1176 & 0.1304 & -0.3333 & 0.3333 \\
\hline $\begin{array}{l}\text { K- } \\
\text { nearest }\end{array}$ & 0.5385 & -0.0909 & -0.0787 & 0.0233 \\
\hline $\begin{array}{l}\text { Logistic } \\
\text { Regressi } \\
\text { on }\end{array}$ & 0.4353 & -0.1294 & -0.0667 & 0.2857 \\
\hline
\end{tabular}

Now calculate MAE by using mathematical equation,

$$
M A E=\frac{\sum_{k=1}^{n} \mid \text { ExpectedValue }_{k}-\text { ObtainedValue }_{k} \mid}{n}
$$

Where $\mathrm{n}$ is total number of samples. Greater value of MAE means the slot have less accuracy and vice versa. That means,

\section{$\operatorname{MAE} \alpha(1 /$ Accuracy $)$}

Results, shown in table 4, justify the importance of slot 1 .

Table 4: Mean absolute error (MAE) results

\begin{tabular}{|l|c|c|c|c|}
\hline $\begin{array}{l}\text { Algorithm } \\
\text { Name }\end{array}$ & $\begin{array}{c}\text { Slot 1 ( } \\
\text { MAE ) }\end{array}$ & $\begin{array}{c}\text { Slot 2 ( } \\
\text { MAE ) }\end{array}$ & $\begin{array}{c}\text { Slot 3 ( } \\
\text { MAE ) }\end{array}$ & $\begin{array}{c}\text { Slot 4( } \\
\text { MAE } \\
\text { ) }\end{array}$ \\
\hline J-48 & 0.3823 & 0.5182 & 0.4192 & 0.4919 \\
\hline SVM & 0.2778 & 0.2778 & 0.2778 & 0.2778 \\
\hline $\begin{array}{l}\text { Naive } \\
\text { Bayes }\end{array}$ & 0.2378 & 0.3778 & 0.5473 & 0.3319 \\
\hline RF & 0.3629 & 0.3953 & 0.4357 & 0.3320 \\
\hline K-nearest & 0.2277 & 0.4033 & 0.4432 & 0.4041 \\
\hline $\begin{array}{l}\text { Logistic } \\
\text { Regression }\end{array}$ & 0.2222 & 0.4166 & 0.4549 & 0.2763 \\
\hline
\end{tabular}

Here the average MAE results are 0.2851, 0.3981, 0.4296 and $0.3523 \mathrm{MAE}$ for slot 1 , slot 2 , slot 3 and slot 4 respectively as shown in figure 5. Slot 1 have minimum value of mean absolute error.

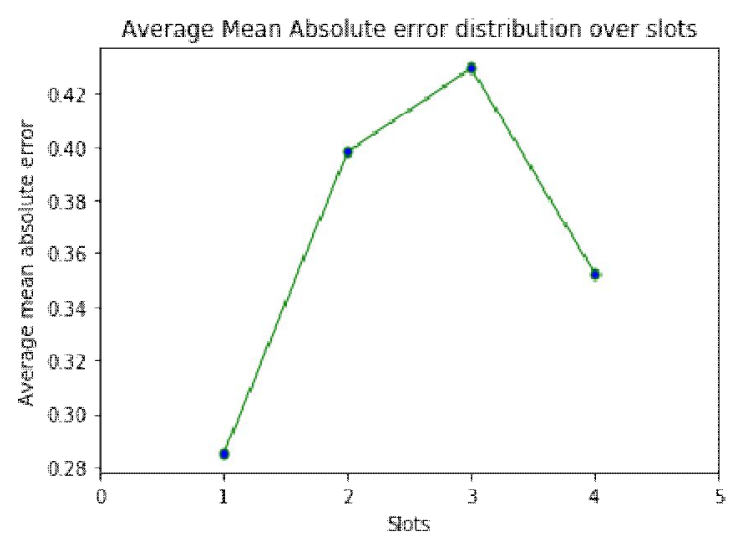

Figure 5: Average mean absolute error (MAE) distribution over slots

Now calculating RMSE by using formula,

$$
=\sqrt{\frac{\sum_{n=1}^{N}\left(\text { ExpectedResult }_{n}-\text { ObtainedResult }_{n}\right)^{2}}{N}}
$$

Where $\mathrm{N}$ is the sample size, results are shown in table 5.

Table 5: Root Mean square error (RMSE) results

\begin{tabular}{|l|c|c|c|c|}
\hline $\begin{array}{l}\text { Algorithm } \\
\text { Name }\end{array}$ & $\begin{array}{c}\text { Slot 1 ( } \\
\text { RMSE ) }\end{array}$ & $\begin{array}{c}\text { Slot 2 ( } \\
\text { RMSE ) }\end{array}$ & $\begin{array}{c}\text { Slot 3 ( } \\
\text { RMSE ) }\end{array}$ & $\begin{array}{l}\text { Slot 4 ( } \\
\text { RMSE } \\
\text { ) }\end{array}$ \\
\hline J-48 & 0.4892 & 0.6406 & 0.5282 & 0.6060 \\
\hline SVM & 0.5227 & 0.5270 & 0.5270 & 0.5270 \\
\hline $\begin{array}{l}\text { Naive } \\
\text { Bayes }\end{array}$ & 0.4732 & 0.6044 & 0.7349 & 0.5659 \\
\hline RF & 0.4287 & 0.4937 & 0.5165 & 0.4220 \\
\hline K-nearest & 0.3752 & 0.5651 & 0.5969 & 0.5561 \\
\hline $\begin{array}{l}\text { Logistic } \\
\text { Regression }\end{array}$ & 0.4714 & 0.6264 & 0.6576 & 0.5227 \\
\hline
\end{tabular}

Here the average RMSE results (Figure 6) are 0.4607, $0.5762,0.5935$ and 0.5332 RMSE for slot 1 , slot 2 , slot 3 and slot 4 respectively. In figure 6 average RMSE graph tilts towards Slot 1 that means slot 1 have minimum RMSE and maximum accuracy.

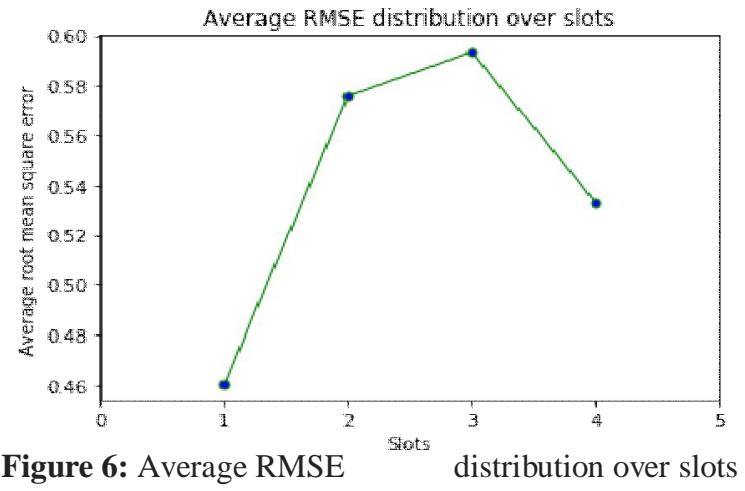

With the help of statistical analysis it is proved that slot 1 have crucial importance to measure the quality of sleep. 


\section{CONCLUSION AND FUTURE SCOPE}

Most of the people often ignore sleep-related diseases due to the time consumption, difficult and costly use of sleep related experiments. After scientific researches, it is believed that in this way, ignoring the importance of sleep is inviting many greater diseases [14, 16, 17]. Realizing the importance of sleep, in this research work, the attempt to summarize and simplify the experiments related to sleep has been made on the basis of testing of data over several time periods. This research has found that sleep quality can also be interpreted based on the data in slot- 1 . Thus, this research will prove effective to reduce the effects of radiation and to make the experiments, related to quality of sleep, brief and simple. In this research, works have been done to reduce the effects of radiation and to make experiments related to sleep quality compact and simple. In the future, the effort to make sleep related experiments more simple and concise will be based on Feature Extraction. This experiment has been successful in extracting important columns through the WEKA tool, but the results will be tested in future research.

\section{REFERENCES}

1. Masayuki Kagawa, Noriyuki Sasaki, KazukiSuzumura and Takemi Matsui (2015), "Sleep stage classification by body movement index and respiratory interval indices using multiple radar sensors", in proc. of 2015 37th Annual international conference of the IEEE engineering in medicine and biology society, DOI: 10.1109/EMBC.2015.7320153, INSPEC accession number: 15584678, 2015

2. Paolo Barsocchi, Monica Bianchini, Antonino Crivello, Davide La Rosa, Filippo Palumbo and Franco Scarselli(2016), "An unobtrusive sleep monitoring system for the human sleep behaviour understanding", in proc. of 2016 7th IEEE international conference on cognitive infocommunications,

DOI: $10.1109 /$ CogInfoCom.2016.7804531, INSPEC accession number: 16564236, 2016

3. Adriana M. Adami, André G. Adami, Tamara L. Hayes and Zachary T. Beattie (2013), "A system for assessment of limb movements in sleep", in proc. of 2013 IEEE 15th international conference on e-health networking, applications and services,

DOI: $\quad 10.1109 /$ HealthCom.20136720712, INSPEC accession number: 14060943, 2013

4. Hsien Wei Tseng, Chien-Da Huang, Liang-Yu Yen, Yu-De Liao and Yung-Wen Lee (2016), "A method of measurement sleep quality by using EEG”, in proc. of 2016 IEEE international conference on consumer electronics-Taiwan, DOI: 10.1109/ICCETW.2016.7521000, INSPEC accession number: 16177900, 2016

5. Shiao-Ping Cheng and Hsing Mei (2012), "A personalised sleep quality assessment mechanism based on sleep pattern analysis", in proc. of IEEE, DOI: 10.1109/IBICA.2012.55, 2012

6. Nico Surantha, Gede Putra Kusuma and Sani M. Isa (2016), "Internet of things for sleep quality monitoring system: a survey", in proc. of 2016 IEEE 11th international conference on knowledge, information and creativity support systems, DOI: 10.1109/KICSS.2016.7951426, INSPEC accession number: 16969170, 2016

7. Alberto Zaffaroni, Sam Coffey, Stephen Dodd, Hannah Kilroy, Graeme Lyon, Damien O'Rourke, Katharina Lederer, Ingo Fiete and Thomas Prenzel (2019), "Sleep staging monitoring based on sonar smartphone technology", in proc. of 2019 41st Annual international conference the IEEE engineering in medicine and biology society, DOI: 10.1109/EMBC.2019.8857033, INSPEC accession number: 19127036, 2019

8. Quya Yan and Chao $\mathrm{Xu}$ (2018), "A method of sleeping state recognition based on pressure-body movement- sleeping model", in proc. of 2018 IEEE 3rd international conference on cloud computing and big data analysis.

DOI: $10.1109 /$ ICCCBDA.2018.8386539, INSPEC accession number: 17844178, 2018

9. Alexander B, Tataraidze, Lesya N. Anishchenko, Lyudmila S. Korostovtseva, Mikhail V. Bochkarev and Yurii V. Sviryaev (2018), "Non-contact respiratory monitoring of subjects with sleepdisordered breathing", in proc. of 2018 IEEE international conference "Quality management, transport and information security, information technologies, DOI: 10.1109/ITMQIS.2018.8525001, INSPEC accession number: 18262535, 2018

10. SupakiDhamchatsoontree, ChaiyapatSirisin, Monika Proncharoensukkul and KonlakornWongpatikaseree (2019), "i-Sleep: intelligent sleep detection system for analyzing sleep behavior", in proc. of 2019 IEEE 4th international conference on information technology, DOI: 10.1109/INCIT.2019.8912047, INSPEC accession number: 19211584, 2019

11. Yuanyuan Liao, Guolin Zhou, Jiuxing Liang, Xiangmin Zhang, XinwenGuo and Yuxi Luo (2019), "Overall population generalities, sex differences, and individual differences in sleep electroencephalography functional connectivity", in proc. of IEEE.

DOI: 10.1109/ACCESS.2019.2950066, Volume 7, 2019

12. Maryam Rvan, Jason Begnaud (2019), "Investigating the effect of short term responsive VNS therapy on sleep quality using automatic sleep staging”, in proc. of IEEE Transactions on biomedical engineering, Volume: 66, Issue: 12,

DOI: 10.1109/TBME.2019. 2903987, INSPEC accession number: 19189150, 2019

13. Shou-Hsiung Cheng, Jui-Chen Huang (2017), "An intelligent sleep quality detection system based on wearable device", in proc. of 2017 IEEE international conference on machine learning and cybernetics, DOI: 10.1109/ICMLC.2017.8108966, INSPEC accession number: 17372997, 2017

14. Mario Giovanni Terzano, Liborio Parrino, Arianna Smerieri, Ronald Chervin, SudhansuChokroverty, Christian Guilleminault, Max Hirshkowitz, Mark Mahowald, Harvey Moldofsky, Agostino Rosa, Robert Thomas and Arthur Walters (2002), “Atlas, rules, and recording techniques for the scoring of cyclic alternating pattern (CAP) in human sleep", in proc. of Elsevier, DOI: 10.1016/s1389- 
Shivam Tiwari et al., International Journal of Advanced Trends in Computer Science and Engineering, 9(3), May - June 2020, 2926 - 2932

9457(01)00149-6, 2002

15. RositsaPoryazova, Esther Werth, Liborio Parrino, Mario Giovanni Terzano and Claudio L. Bassetti (2011), "Cyclic alternating pattern in narcolepsy patients and healthy controls after partial and total sleep deprivation", in proc. of clinical neurophysiology 122 (2011) 1788-1793 Elsevier, DOI: 10.1016/j.clinph.2011.02.028, 2011

16. Carole L. Marcus, John L. Carroll, David F. Donnelly and Gerald M. Loughlin (2008), "Sleep in children Development changes in sleep pattern", in proc. of Lung biology in health and disease, Second edition, Publisher: Informa healthcare USA, Inc., ISBN-10:142006080-5 and ISBN-13:978-1-4200-6080-5, 2008

17. Charles P. Pollak, Michael J. Thorpy and Jan Yager (2010), "The encyclopaedia of sleep and sleep disorder, Third edition", Publisher: Facts On File, An imprint of infobase publishing, New York NY 10001, ISBN-13:978-08160-6833-3, ISBN-10:0-8160-6833$\mathrm{X}$ and ISBN: 978-1-4381-2577-0, 2010
18. Young Soo Jang, Young Han Kook, Jeong-lae Kim, Hyun-Woo Jeong., "Development of the costeffective, miniaturized vein imaging system with enhanced noise reduction", International Journal of Advanced Trends in Computer Science and Engineering, Volume 8, No.6, November - December 2019.

https://doi.org/10.30534/ijatcse/2019/80862019

19. Irma T. Plata, "Development and Testing of Embedded System for Smart Detection and Recognition of Witches Broom Disease on Cassava Plants using Enhanced Viola-Jones and Template Matching Algorithm", International Journal of Advanced Trends in Computer Science and Engineering, Volume 8, No.5, September - October 2019. 